\title{
REALISME DALAM KEPENTINGAN NASIONAL INDONESIA MELALUI FORUM KONFERENSI ASIA AFRIKA (KAA) DAN GERAKAN NON BLOK (GNB)
}

\author{
Taufan Herdansyah Akbar, Agus Subagyo, \& Jusmalia Oktaviani
}

\begin{abstract}
Realism is an approach and paradigm that is in international relations, Realism began to be debated during World War II (World War II) because of the failure of the League of Nations ( $L B B$ ). $L B B$ is the brainchild of idealists who are considered to have failed to prevent war and create peace. Realism existed even before the paradigm debate which was later called classical realism with one of its characters being Niccolo Machiavelly. Niccolo Maciavelly's style of realism emphasizes that human nature is egositically and creates an anarchic world. In this study the research team wanted to prove that what Niccolo Machiavelly delivered was not merely increasing military power merely to create peace, but negotiation and diplomacy methods were also instruments of the State in achieving its national interests in realism like Indonesia. The national interests of Indonesia are everything for Indonesian politicians and the existence and power of Indonesia is the goal of Indonesia's interests to avoid war. Therefore Indonesia must have played its role in the Asian-African Conference and the Non-Aligned Movement at that time as an instrument of achieving national interests in Realism. This research will use qualitative research methods with a historical approach. The results of this study provide answers that Realism is not merely militaristic but also a role as a rational actor.
\end{abstract}

Keywords: Realism, Indonesia, KAA, NAM.

\section{Latar Belakang}

Persaingan pada Perang Dingin merupakan upaya Blok Barat dan Blok Timur untuk memperluas kepentingan dan pengaruh. Sasaran utama perebutan penguasaan wilayah-wilayah strategis di dunia dengan melaksanakan penyebaran ideologi (Kemendag:2006). Dua ideologi yang saling bertentangan yaitu liberalisme yang disebarkan oleh AS yang menekankan kepada kebebasan individu untuk mengembangkan segala 
potensi. Sedangkan komunisme yang dipegang oleh Uni Soviet melakukan penyamarataan agar tidak ada kelas-kelas masyarakat, yang bertujuan untuk kesejateraan sosial (Akademik:2015).

Sementara itu, rakyat di Asia dan Afrika masih mengalami keterkebelakangan, kemiskinan, kelaparan, sebagai akibat dari peperangan, penjajahan dan perbudakan yang dilakukan oleh negaranegara yang termasuk dalam Blok Barat maupun Blok Timur (KAA:2015). Prioritas negara di Asia dan Afrika adalah membebaskan diri dari dominasi negara-negara adidaya dan membangun negara masing-masing berdasarkan prinsip-prinsip kemerdekaan, keadilan dan perdamaian. Indonesia menetapkan kebijakan luar negerinya sejak awal kemerdekaannya yaitu bebas aktif (KAA:2015). Maksud dari bebas aktif yaitu tidak berpihak kepada blok manapun, tidak berdasarkan kepentingan asing, tetapi ikut aktif dalam menghapuskan penjajahan serta menciptakan perdamaian dunia (KAA:2015). Dalam kondisi seperti ini, lahir dorongan kuat dari para pemimpin dunia ketiga untuk keluar dari tekanan dua negara adidaya. Presiden Indonesia Soekarno, Perdana Menteri India Jawaharlal Nehru dan beberapa pemimpin dari Asia dan Afrika merasakan polarisasi yang terjadi pada masa Perang Dingin adalah tidak jauh berbeda dengan kolonialisme dalam bentuk yang lain.

Kepemimpinan Presiden Soekarno, peran Indonesia dalam GNB dapat perhatian dan publikasi yang tinggi dari negara anggota dan AS (KAA:2015). Selain sebagai pendiri, Soekarno juga ditugaskan untuk menyampaikan tujuan dan hasil Konferensi Non Blok kepada Presiden AS Kennedy di Washington pada tanggal 12 September 1961. Soekarno mencoba memperkenalkan konsep perjuangan baru kepada GNB, konsep yang membagi dunia ke dalam dua kubu yang bertarung, yakni New Emerging Forces (NEFO, negara-negara yang baru merdeka dari jajahan negaranegara kapitalis imperialis) dan Old Established Forces (OLDEFO, negaranegara kapitalis imperialis yang ingin melanggengkan dominasinya) (KAA:2015). NEFO merupakan gabungan negara yang menghendaki 
hilangnya kapitalisme, imperialisme, kolonilaisme dan segala manifestasinya. Sedangkan GNB adalah gerakan politik yang tidak memihak Blok Barat dan Blok Timur.

Sebagai salah satu penggerak GNB dan NEFO, Indonesia berkomitmen dalam mencapai kesetaraan hak setiap bangsa dan ikut serta dalam memelihara perdamaian dunia. Untuk mengejawantahkan pergerakan NEFO, Soekarno mendirikan Games of the New Emerging Forces (GANEFO) sebagai tandingan Olympic Games yang dinilai terlalu dikuasai negaranegara imperialis dan Conference of the the New Emerging Forces (CONEFO) sebagai tandingan PBB. GANEFO yang pertama berhasil diselenggarakan di Jakarta pada bulan Nopember 1963. Sedangkan CONEFO yang direncanakan dilangsungkan tahun 1966 gagal dilaksanakan karena Bung Karno digulingkan dari kedudukannya padatahun 1965-1966 (GNB:2015).

Paparan diatas menarik untuk diteliti, terutama untuk mengkaji kemungkinan Indonesia dalam keanggotaan KAA dan GNB justru merupakan bentuk yang tidak umum daripada Realisme. Hal yang menjadi ketertarikan peneliti ialah Perang Dingin yang sudah berakhir sejak awal 1990-an namun forum KAA dan GNB tetap dipertahankan oleh Indonesia sebagai wadah pencapaian politiknya, atau jika KAA dan GNB tidak berarti bagi Indonesia maka buat apa Indonesia mempertahankannya. Dengan demikian, rumusan masalah bagi penelitian ini adalah Bagaimana Realisme dapat menjawab kepentingam Nasionalisme Indonesia dalam keanggotaan dalam Konferensi Asia Afrika (KAA) dan Gerakan Non Blok (GNB)? Tujuan penelitian ini untuk menjawab bahwa paradigma dan perdebatan besar dalam hubungan internasional tidak dapat dilihat sebagai hitam putih dengan batas-batas yang jelas melainkan melalui pandangan subjektif peneliti secara historis sesuai paradigm tradisionalis dari perdebatan ke dua hubungan internasional. 


\section{PEMBAHASAN}

\section{Sejarah Konferensi Asia-Afrika dalam Gerakan Non Blok (GNB)}

Terselenggarakannya Konferensi Asia-Afrika (KAA) yang bertempat di Bandung pada tahun 1955 ini adalah wadah bagi berjalannya proses pembentukan GNB. Setelah berakhirnya Perang Dunia II yang dimenangkan oleh sekutu telah menciptakan dua blok negara super power yakni antara Blok Barat yang menganut sistem kapitalis di mana Amerika Serikat sebagai pemimpinnya dan Blok Timur yang menganut ideologi komunis di mana Uni Soviet sebagai pemimpinnya. Hal ini telah menciptakan permasalahan baru di belahan dunia, sehingga menjadi faktor pemicu Perang Dingin. Isu yang terjadi pada masa itu yakni tentang pengembangan senjata nuklir oleh kedua blok yang mengancam keamanan dunia. Perserikatan Bangsa-Bangsa (PBB) pada saat itu belum berhasil meredakan ketegangan antara kedua blok tersebut, sedangkan negaranegara di kawasan Asia dan Afrika telah menderita akibat masalah yang ditimbulkan.

Terdapat 3 permasalahan utama yang menjadi bahan pembicaraan di Konferensi Asia-Afrika yakni meliputi, kerjasama ekonomi, kebudayaan, hingga politik. Untuk ranah politik membahas tentang Hak Asasi Manusia (HAM), terkait masalah bagaimana menentukan nasib sendiri, pelucutan senjata serta koeksistensi. 'Semangat Bandung' telah menjadi slogan bagi mereka yakni negara-negara yang baru merdeka untuk menegaskan bahwa mereka berhak dan bebas dalam menentukan nasibnya sendiri. Kekuatan baru terlahir dari negara-negara yang pada saat itu baru saja merdeka atas penjajahan yang dialami selama bertahun-tahun. Cita-cita ini sejalan dengan Indonesia dan negara-negara di kawasan Asia dan Afrika lainnya yang menjunjung rasa senasib dan perlu bangkit. 'Semangat Bandung' menjadi jiwa dari Konferensi Asia-Afrika untuk menggelorakan kebangkitan negara-negara bang baru merdeka. 
Di dalamnya, dirumuskan Dasasila Bandung yang berisi penghormatan atas hak-hak dasar manusia, asas, serta tujuan yang telah dimuat dalam Piagam PBB. Diantaranya: Menghormati kedaulatan dan integrasi teritorial (keutuhan wilayah) seluruh bangsa; Mengakui persamaan semua ras dan persamaan semua bangsa besar (adi kuasa) maupun bangsa yang kecil; Tidak turut intervensi atau campur tangan dalam persoalan negara lain; Menghormati hak dari tiap-tiap bangsa untuk senantiasa mempertahankan diri secara mandiri atau kelompok; Tidak menggunakan segala peraturan-peraturan dari pertahanan kolektif untuk bertindak sesuai dengan kepentingan khusus dari salah satu negaranegara besar serta tidak melakukan tekanan terhadap negara lain; Tidak melakukan segala tindakan yang melibatkan ancaman agresi ataupun penggunaan kekerasan terhadap integritas nasional atau kemerdekaan suatu negara; Menyelesaikan segala bentuk perselisihan di ranah internasional melalui jalan damai seperti halnya perundingan, persetujuan arbitrase atau melalui hukum dan juga cara damai lainnya sesuai pilihan dari pihak yang bersangkutan dan tetap sesuai dengan Piagam PBB; Memajukan segala bentuk kepentingan bersama melalui kerjasama; dan Menghormati hukum dan segala kewajiban-kewajiban di kancah internasional.

Peran Dasasila Bandung telah memberikan pengaruh dan menjadi awal berdirinya gerakan negara-negara di kawasan Asia-Afrika untuk menegaskan posisinya di tengah Perang Dingin yang sedang berkecamuk. GNB memiliki tujuan untuk mengidentifikasi serta memperdalam mengenai permasalahan yang terjadi di dunia dan berupaya membentuk kebijakan bersama negara anggota. Gerakan Non Blok (GNB) telah diprakarsai oleh Presiden Soekarno bersama para pemimpin negara lainnya seperti Gamal Abdul Nasser (Presiden Mesir), Kwame Nkrumah (Presiden Ghana), Jawaharlal Nehru (Perdana Menteri India), dan Joseph Broz Tito (Presiden Yugoslavia). Mereka menegaskan negara-negara Asia-Afrika untuk tidak turut terpengaruh oleh dominasi Blok Barat maupun Blok Timur. 
Konferensi Tingkat Tinggi I (KTT I) GNB yang bertempat di Beograd, Yugoslavia pada tanggal 1-6 September 1961, didalamnya ditegaskan peran GNB tidak mengarah pada peran yang pasif dalam politik internasional, melainkan bagaimana memposisikan negara secara independen dan bertindak sesuai dengan kepentingannya masing-masing.

\section{Keanggotaan Indonesia dalam Konferensi Asia-Afrika (KAA)}

KAA memiliki pengaruh sangat besar kepada Indonesia dan kepada bangsa-bangsa di Asia Afrika secara keseluruhan. Indonesia mendapat dukungan dari banyak negara mengenai masalah Papua. Setelah KAA, ketegangan Republik Rakyat Cina (RRC) dengan Amerika Serikat tentang sengketa Taiwan mulai mencair dengan berbagai perundingan. Selain itu, jumlah negara yang merdeka di wilayah ini semakin banyak. Yang paling besar adalah berdirinya peran Indonesia dalam Gerakan Non Blok. Gerakan yang menjadikan negara-negara tidak berpihak pada blok mana pun yang saat itu sedang berebut pengaruh terhadap negara-negara berkembang. Peran Indonesia dalam KAA sangat strategis. Peran tersebut, yaitu:

1. Pemrakarsa

Indonesia menjadi salah satu negara penggagas KAA memiliki peran sentral serta kontribusi terhadap KAA

2. Tempat Konferensi

Tempat KAA pertama kali adalah di Indonesia. Tepatnya di Gedung Merdeka, Bandung pada tanggal 18 sampai 24 April 1955. Konferensi pendahuluan sebelum diadakannya KAA juga terjadi di Indonesia, yaitu Konferensi Bogor. Penyelenggraan KAA yang kedua juga diadakan di Indonesia, yaitu pada tanggal 19 sampai 23 April 2015 di Jakarta dan pada tanggal 24 April di Bandung. Pada KAA yang kedua ini dihadiri oleh 89 negara Asia $\begin{array}{lllll}\text { Afrika dari } & 109 \text { negara yang ada. }\end{array}$ 
3. Dasasila Bandung

Indonesia sebagai negara yang berperan penting bagi terumuskannya dasasila Bandung (hasil KAA Bandung).

Selain itu, keikutsertaan Indonesia dalam Konferensi Asia Afrika memiliki beberapa kepentingan. Dalam teori Kepentingan Nasional menurut Lembaga Ketahanan Nasional "Tindakan suatu negara selalu didasarkan pada kepentingan nasional, yakni kepentingan ipoleksosbudhankam". Kepentingan nasional Indonesia dalam KAA diantaranya:

a. Kepentingan ideologi, menghindari sphere of influence antara sosialisme dan kopitalisme dalam perang dingin.

b. Kepentingan politik, mempromosikan pengakuan kedaulatan Repulik Indonesia dalam kancah internasional

c. Kepentingan ekonomi, memajukan ekonomi, investasi, \& perdagangan antar negara di dunia

d. Kepentingan sosial budaya, memperkokoh jalinan kerjasama budaya "ketimuran"

e. Kepentingan hankam, menjaga indepensi / netralitas antara Blok Barat dan Blok Timur

Sedangkan kepentingan nasional menurut Jack C Plano dan Roy Olton yaitu "Kepentingan nasional adalah kepentingan vital yang terdiri dari : Independence, self preservation, territorial integrity, military security, economic well-being"

a. Independence, untuk menunjukkan kemandirian politik luar negeri yang bebas aktif.

b. Self preservation, untuk meneguhkan sikap Indonesia yang anti imperialisme-kolonialisme.

c. Territorial integrity, untuk meminta dukungan negara-negara Asia Afrika tentang pembebasan Irian Barat dari hegemoni Belanda 
d. Military security, untuk menunjukkan bahwa Indonesia telah aman dari berbagai ancaman penjajahan dengan jaminan militer

e. Economic Well-being, untuk menjalin kerjasama perdagangan antar negara-negara Asia Afrika

\section{Keuntungan dan Manfaat Bagi Indonesia dalam Konferensi Asia-Afrika}

Adanya peran serta keterlibatan Indonesia dalam Koferensi Asia-Afrika (KAA) tentu telah membawakan keuntungan bagi Indonesia sendiri. Terlebih lagi posisi Indonesia sebagai negara penyelenggara sekaligus memimpin jalannya konferensi, sehingga dampak dari terselenggaranya konferensi ini akan menyelipkan nilai tambah dari berbagai aspek terhadap Indonesia sebagai tuan rumah. Keuntungan yang diperoleh Indonesia ini tidak terlepas dari pencapaian kepentingan nasional suatu negara yang pada akhirnya jika kepentingan tersebut dapat tercapai maka akan melahirkan manfaat pula bagi negara tersebut. Hal ini sejalan dengan konsep kepentingan nasional yang berasal dari penganut pendekatan realisme sebagai berikut, "Kepentingan nasional diartikan sebagai kemampuan minimum negara bangsa dalam memelihara identitas fisik, identitas politik, dan identitas kulturalnya, dari gangguan negara bangsa lain”, (Hans J. Morgenthau, 1996). Berdasarkan aspek-aspek yang disebutkan pada konsep tersebut, maka terdapat keuntungan yang didapat oleh Indonesia sebagai berikut :

a. Pertama, untuk mengenalkan identitas fisik. Sebagai penyelanggara dan tuan rumah Konferensi Asia-Afrika di tanah air, maka Indonesia dapat mengenalkan secara fisik wilayah kedaulatan Negara Kesatuan Republik Indonesia sebagai nationstate. Negara-negara yang berasal dari Asia dan juga Afrika yang datang ke Indonesia akan mengetahui bahwa Indonesia sudah menjadi negara berdaulat sejak memproklamasikan $\begin{array}{lllll}\text { kemerdekaannya } & \text { pada } & 17 & \text { Agustus } & 1945 .\end{array}$ 
b. Kedua, untuk mengenalkan identitas politik. Dalam penyelenggaraan Konferensi Asia-Afrika Indonesia sekaligus dapat mengenalkan sistem pemerintahannya yakni, sistem pemerintahan parlementer. Dan juga memeperkenalkan bahwa Indonesia menganut sistem pemerintahan yang demokratis, dimana kekuasaan berada di tangan rakyat.

c. Ketiga, untuk mengenalkan identitas kultural. Dengan kehadiran negara-negara lain di Indonesia dapat sekaligus menjadi anjang bagi Indonesia untuk mempromosikan kekayaan budaya yang dimiliki. Kondisi Indonesia yang memiliki keberagaman kekayaan budaya, adat istiadat, suku, etnis, bahasa serta memiliki kerukunan antar umat beragama akan mendapatkan perhatian dan ketertarikan dari negara pendatang.

Selanjutnya, ada pula manfaat yang dirasakan oleh Indonesia dengan terselenggaranya Konferensi Asia-Afrika. Manfaat yang dirasakan tersebut datang dari hasil yang diperoleh konferensi itu sendiri. Dengan terlaksananya Konferensi Asia-Afrika, Indonesia dapat meningkatkan eksistensi negara-negara yang memilih untuk tidak memihak kepada salah satu blok yakni, Blok Barat dan Blok Timur. Lahirnya sebuah aliansi negara-negara yang tidak berpihak ke dalam dua kubu tersebut tentu memiliki tujuan didalamnya. Kelompok aliansi ini akan menjalin kerjasama dalam segala bidang demi mencapai kepentingannya sehingga terhindar dari pengaruh kedua kubu. Indonesia dapat merasakan manfaat atas pencapaian kepentingan nasionalnya mulai dari penguatan ideologi, peningkatan pertahanan, ekonomi, hingga ke tata internasional. Hal ini sejalan dengan konsep kepentingan nasional menurut Donald E. Nuchterlin, "Kepentingan nasional diarahkan untuk mencapai manfaat aspek ideologi, pertahanan, ekonomi dan tata internasional negara bersangkutan" (Donald E. Nuchterlin, 1976). Berdasarkan aspek-aspek 
tersebut, maka Indonesia merasakan manfaat dari terselenggaranya Konferensi Asia-Afrika, yakni diantaranya :

a. Manfaat Ideologi, Indonesia menjadi contoh bagi negara-negara Asia dan Afrika sebagai negara yang menerapkan politik luar negerinya yang tidak memihak kepada Blok Sosialis maupun Blok Kapitalis.

b. Manfaat Pertahanan, Indonesia dipandang oleh dunia sebagai negara yang mempunyai "banyak sekutu" meskipun tidak memihak kepada dua blok. Negara Indonesia menjadi negara yang disegani sebab dengan memiliki "banyak teman" tentu akan memperkuat Indonesia dalam bidang pertahanan.

c. Manfaat Ekonomi, Indonesia mampu menciptakan kesepakatan terkait sistem perdagangan dan investasi antara negara-negara Asia-Afrika, seperti Cina, Jepang, dengan Federasi Afrika Tengah.

d. Manfaat Tata Internasional, Indonesia dapat disegani oleh negaranegara di dunia sebab telah menjadi wadah tercetusnya Gerakan Non-Blok (GNB) pada 1961.

Terselanggaranya Konferensi Asia-Afrika tentu akan menciptakan suatu pencapaian kepentingan nasional setiap negaranya. Hal ini menunjukkan bahwa tujuan dari terbentuknya suatu kelompok yakni tak lain menjadi wadah bagi anggotanya untuk mencapai segala kepentingan negara itu sendiri. Keuntungan serta manfaat yang dirasakan oleh Indonesia pun telah membantu terwujudnya kepentingan nasional. Selain itu, posisi Indonesia sebagai tuan rumah pun tentu memberikan perkembangan pesat dalam eksistensinya di kancah internasional.

\section{Signifikansi Indonesia di Konferensi Asia-Afrika (KAA) dalam masa sekarang}




\section{KAA Pasca Perang Dingin}

KAA Bandung 1955 lahir didorong oleh adanya situasi, kondisi dan suasana kebatinan internasional yang sarat akan nuansa perang dingin (Blok Barat vs Blok Timur) dan kolonialisme / penjajahan. Namun, saat ini, Perang Dingin telah berakhir, sehingga KAA Bandung harus melakukan reformulasi dan reorientasi karena Blok Timur sudah hancur, penjajahan secara fisik sudah tidak ada (kecuali Palestina), dan sekarang muncul super power Amerika Serikat (AS) satu-satunya. KAA Bandung Tahun 2005 untuk peringati 50 tahun KAA mengarahkan agar supaya KAA diarahkan pada kemitraan strategis perdagangaan, investasi, dan bisnis antara negara AsiaAfrika mengingat kemiskinan, pengangguran, dan kelaparan di Afrika akibat perang saudara.

Dalam perspektif organisasi internasional, KAA bukan merupakan organisasi regional atau organisasi internasional. KAA hanya wadah bagi bertemunya para kepala negara Asia dan Afrika untuk mendiskusikan isuisu krusial. Adanya kenyataan saat ini bahwa Asia tidak begitu berkepentingan dengan Afrika karena tidak menguntungkan secara ekonomi. Asia justru saat ini berkepentingan dengan kawasan Amerika dan Eropa (ASEM, APEC). Dengan kata lain, di era globalisasi ekonomi \& pasar bebas $\&$ perdagangan bebas saat ini, secara kasar dikatakan bahwa "Afrika butuh Asia, namun Asia kurang membutuhkan Afrika"

Keberadaan GNB sebagai persatuan yang berkepentingan dalam PBB untuk menekan negara adikuasa seperti Amerika Serikat. Selain itu dengan adanya keanggotaan baru juga menunjukkan relevansi GNB dan 27 negara yang meminta Indonesia sebagai penyelenggara bersama Mesir sebagai ketua GNB saat itu, diantaranya Jerman, Rusia, AS dan Belgia. Munculnya tantangan-tantangan global baru sejak akhir abad ke-20 telah memaksa GNB untuk terus mengembangkan kapasitas dan arah kebijakannya agar sepenuhnya mampu menjadikan keberadaannya tetap relevan, tidak hanya bagi anggotanya tetapi juga lebih terkait dengan sumbangannya dalam menghadapi tantangan tersebut. Tantangan yang dimaksud dewasa ini 
antara lain adalah isu menonjol yang terkait dengan masalah terorisme, merebaknya konflik intra dan antar negara, pelucutan senjata, serta dampak globalisasi di bidang ekonomi dan informasi teknologi. Isu-isu tersebut telah menjadikan GNB perlu menyesuaikan kebijakan dan perjuangannya yang dalam konteks ini GNB memandang perannya tidak hanya sebagai obyek, tetapi sebagai mitra seimbang dan bagian dari solusi masalah dunia.

Munculnya tantangan-tantangan global baru sejak awal abad ke21 telah memaksa GNB terus mengembangkan kapasitas dan arah kebijakannya agar sepenuhnya mampu menjadikan keberadaannya tetap relevan tidak hanya bagi negara-negara anggotanya tetapi lebih terkait dengan kontribusinya dalam menghadapi tantangan-tantangan tersebut. GNB terus berupaya dalam mencari solusi serta transformasi menghadapi persoalan dalam negeri seperti masalah ekonomi dan sosial. Selain itu juga, tuntutan menjaga perdamaian dunia juga menjadi komitmen. Hal ini bisa dilihat sejak pertemuan di Jakarta pada Konferensi Tingkat Tinggi (KTT) X tahun 1992 hingga KTT XVI di Teheran pada 2012. Dalam perkembangan isu internasional, maka pasca Perang Dingin, GNB melakukan pengembangan agenda kerjasama dalam berbagai bidang. Pengembangan kerjasama ini mengikuti dinamika global yang bukan lagi isu keamanan tradisional, namun isu kemanan non-tradisional. Peneliti berpendapat bahwa GNB memerlukan revitalisasi merujuk beberapa KTT GNB yang banyak membahas kerjasama non-tradisional.

\section{Upaya Transformasi Gerakan Non Blok (GNB)}

Relevansi GNB dengan kehidupan sosial masa kini dipertanyakan, namun Indonesia akan membuktikan bahwa GNB masih diperlukan dunia. Salah satu cara untuk relevansi fungsi GNB adalah melakukan transformasi GNB untuk memenuhi kebutuhan negara-negara yang masih miskin, terbelakang, dan syarat akan kesenjangan ekonomi. Namun, Perang Dingin yang terjadi selama empat dekade berakhir sehingga 
keberadaan blok yang bertikai pun sudah hilang, bagaimana agara GNB teteap relevan, ditengan persaingan multipolar dalam memperkuat posisi negara-negara berkembang lainnya. Kemudian lahirlah Kerjasama SelatanSelatan dimana istilah GNB sudah tidak lagi sering digunakan, peneliti berkesimpulan sebab istilah GNB mengacu pada Perang Dingin yang menekankan pada blok (Wuryandari, 2016).

\section{Kerjasama Selatan Selatan}

Setelah KTT Jakarta, GNB terus bekerja keras dan berhasil meluncurkan kembali Dialog Utara-Selatan dan mengintensifkan Kerjasama Selatan-Selatan Seperti yang ditunjukkan oleh Presiden Soeharto selama KTT, bahwa hubungan Utara-Selatan tidak dapat dirubah sementara Kerjasama Selatan-Selatan masih dengan semangat yang sama yaitu mereduksi kesenjangan.

Sejak The Jakarta Summit, pada tahun 1992, GNB lebih berfokus pada kerjasama. Contohnya adalah inisiatif GNB mentransformasi kegiatan dan perjuangannya ke Kerjasama Selatan-Selatan (KSS), yang telah memiliki dampak terbesar pada Forum Asia-Afrika yang diadakan pada bulan Desember 1994 di Bandung. Forum ini, disebut sebagai "Forum Bandung", telah menjadi dasar pembentukan yang kuat untuk promosi kerjasama pembangunan antara negara-negara Asia dan Afrika, serta dapat menjadi model bagi upaya KSS. Sejak The Jakarta Summit, pada tahun 1992, GNB lebih berfokus pada kerjasama. Contohnya adalah inisiatif GNB mentransformasi kegiatan dan perjuangannya ke Kerjasama SelatanSelatan (KSS), yang telah memiliki dampak terbesar pada Forum AsiaAfrika yang diadakan pada bulan Desember 1994 di Bandung. Forum ini, disebut sebagai "Forum Bandung", telah menjadi dasar pembentukan yang kuat untuk promosi kerjasama pembangunan antara negara-negara Asia dan Afrika, serta dapat menjadi model bagi upaya KSS (Kementrian Luar Negeri 


\section{Kesimpulan}

Dengan perspektif realisme, peranan Indonesia dalam penyelenggaraan Konferensi Asia-Afrika tidak terlepas dari tujuan Indonesia dalam mencapai kepentingan nasionalnya. Hal ini sejalan dengan definisi mengenai konsep kepentingan nasional yaitu, "Tindakan suatu negara selalu didasarkan pada kepentingan nasional, yakni kepentingan ideologi, politik, ekonomi, sosial budaya, serta pertahanan dan keamanan". Untuk aspek ideologi, Indonesia tidak ingin adanya negara-negara di kawasan Asia-Afrika yang terpengaruh oleh dominasi Blok Barat yang menganut sistem kapitalis dan Blok Timur yang menganut sistem komunis. Dari aspek kepentingan politik, yakni sebagai jalan untuk menunjukkan bahwa Indonesia merupakan negara berdaulat di kancah internasional. Kemudian dari aspek ekonomi, Indonesia mampu membuat kesepakatan terkait kegiatan perdagangan dan investasi yang dapat dijalin melalui kerjasama oleh negara-negara di kawasan Asia dan Afrika. Selanjutnya dari aspek budaya, Indonesia beserta negara-negara di kawasan Asia dan Afrika dapat menjalin kegiatan pertukaran budaya maupun penguatan budaya "ketimuran". Dan juga dari aspek pertahanan dan keamanan, Indonesia akan dipandang oleh dunia sebagai negara yang memiliki "banyak sekutu" dan "banyak teman" sehingga memungkinkan tak ada negara luar yang berani mengancam kedaulatan Negara Kesatuan Republik Indonesia.

Dengan perspektif realisme maka, dapat ditelusuri mengenai bentuk kepentingan nasional dari adanya keikutsertaan Indonesia dalam Konferensi Asia-Afrika. Hal ini memperlihatkan bahwa setiap negara tentu memiliki tujuan untuk mencapai kepentingan nasionalnya masing-masing. Namun, hal tersebut bukan semata-mata hanya mementingkan tercapainya tujuan dari salah satu negara, tetapi untuk menunjukkan bahwa realisme tidak selalu mengandalkan kekuatan untuk mewujudkan perdamaian, tetapi dengan berdiplomasi dan bernegosiasi pun merupakan instrumen bagi suatu negara dalam memenuhi kepentingannya. Penelitian ini perlu disempurnakan untuk lebih mengetahui bagaimana kepentingan nasional 
yang ingin dicapai Indonesia dalam penyelenggaraan Konferensi Asia-Afrika yang masih tetap diadakan hingga saat ini. Selain itu, penelitian ini diharapkan dapat berguna untuk kemajuan ilmu karena, penelitian ini menunjukan bahwa realisme tidak hanya membahas tentang meningkatkan power masing-masing negara untuk mencapai kedamaian namun, memperlihatkan bagaimana negara-negara melakukan diplomasi dalam mencapai kepentingan nasional.

Negara diharapkan untuk tetap konsisten dalam menjaga dan memperjuangkan kepentingan nasional dalam konferensi ini karena hal ini sangat menguntungkan bagi Indonesia dengan terjalinnya kerjasama seperti Kerjasama Selatan-Selatan (KSS) sebagai bentuk dari transformasi GNB. Penelitian ini dapat dijadikan sebagai bahan referensi bagi penulispenulis lainnya dalam membuat sebuah karya tulis ataupun penelitian.

\section{DAFTAR PUSTAKA}

Abdul Hadi Adnan, Perkembangan Hubungan Internasional di Afrika. Bandung : Angkasa, 2008

Anak Agung Banyu Perwita dan Yanyan Mochammad Yani, Pengantar IlmuHubungan Internasional. Bandung : Rosda, 2005

A.W Widjaja, Indonesia Asia Afrika Non Blok Politik Bebas Aktif, Jakarta : Bina Aksara, 1986

Coplin, William. D, Inroduction to International Politics : Theoritical Overview. Chicago : Marhkam Publishing Company, 1971

Creswell, John W, Research Design : Pendekatan Kualitatif, Kuantitatif dan Campuran. Yogyakarta : Pustaka Pelajar, 2010

E.Y.S Lapian, Non Blok Dewasa Ini. Jakarta : , 1979

Graham, Evan dan Newham, Jefney, The Distionary of World Politic : A Reference Guide to Concept, Ideas and Institutions.New York: Harvester Wheatshaf, 1990

Howard H lenter. Foreign Policy Analysis : A Comperative And Conceptual Approach. 
Ohio: A Bell and Howell Company, 1999

Iva Rachmawati, Memahami Perkembangan Studi Hubungan Internasional. Yogyakarta: Aswaja Pressindo, 2012

K.J Holsti, Internasional Politic : A Framework for Analysis. New Jersey : Prentice- Hall Internasional Inc., 1992

Lexy J. Moleong, Metode Penelitian Kualitatif: Edisi revisi, Bandung : Rosda, 2006

Roeslan Abdulgani, The Bandung Connection. Cetakan ke-4, Museum KAA : Direktorat Jenderal Informasi dan Diplomasi Publik Kementerian Luar Negeri RI, 2015

Toma, Peter A. , Gorman, Robert F, International Relations: Understanding Global Issues. New York : Brooks Cole Publishing Company. 1991

, Report of The Chairman of The Non Aligned Movement. Jakarta : Gramedia Widiasarana Indonesia, 1997

,Badan Litbang Departemen Luar Negeri RI, Non-Blok Dewasa Ini. Jakarta: Perpustakaan Badan Litbang Departemen Luar Negeri RI, 1990

,Departemen Luar Negeri Republik Indonesia, Sejarah Diplomasi RI Dari Masa Ke Masa Periode 1960-1965. Jakarta : Departemen Luar Negeri Republik Indonesia, 1996

Kementerian Pertanian Republik Indonesia, Badan Litbang Pertanian, "Kerjasama Luar Negeri", http://www.litbang.pertanian.go.id/kerjasama/kln

Kementerian Riset, Teknologi dan Pendidikaan Tinggi, "Kemitraan Negara Berkembang",http://knb.dikti.go.id/files/Application\%20Guidance\% 202015.pdf.

Kementerian Riset, Teknologi dan Pendidikaan Tinggi, "Beasiswa Unggulan Indonesia", http:/ / beasiswaunggulan.kemdiknas.go.id/profile.

Kementerian Riset, Teknologi dan Pendidikaan Tinggi, "Developing country Patnership On Scholarship Program” http://knb.dikti.go.id/index.php.

Museum Konperensi Asia Afrika, "Sejarah Konferensi Asia Afrika", http://asianafricanmuseum.org/sejarah-konferensi-asia-afrika/.

Non Alignment Movement, "General Background, NAM", http:// namiran.org/background-general/. 
Supriyadi, "Daftar KTT Non Blok I sampai XV", http://www.sejarahnegara.com/2014/09/daftar-ktt-non-blok-i-sampai-xv.html

The World Bank, "Pendidikan Tinggi dapat Memberikan Kontribusi yang Lebih Besar bagi Pembangunan Indonesia", http://www.worldbank.org/in/news/pressrelease/2011/10/13/higher-education-contribute-even-moreindonesia-development.

Time Higher Educations, "World University Rankings 2014-15", https://www. timeshighereducation.co.uk/world-universityrankings/2015/world-university-rankings\#/search/ singapore.

Transformasi, http://kbbi.web.id/transformasi.

Transformation,http://managementhelp.org/organizationalchange/transfor mational.htm.

United Nations Development Program South-South Cooperation, "What is South-South http://ssc.undp.org/content/ssc/about/what_is_ssc.html.

United Nation, "The Millennium Development Report 2012" (pdf from http://www.un.org/millenniumgoals/reports.shtml. 